Iin Lidia Putama Mursal, Maulana Mahmuddin, Muhammad Afif Firmansyah, Edwin Pribadi, Rifqi Azhar Fawih, Komarudin, Taopik Zaenal Muttakqin, Wida Nengsih,

Rosalinda, Windi Nabila

Vol. 3 No 1, Februari 2021

ISSN 2657-0203

e-ISSN 2686-0244

\title{
RANCANG BANGUN SISTEM PELAYANAN INFORMASI UMKM DESA RAWAGEMPOL WETAN BERBASIS WEBSITE
}

\author{
Iin Lidia Putama Mursal ${ }^{1}$, Maulana Mahmuddin ${ }^{2}$, Muhammad Afif \\ Firmansyah $^{3}$, Edwin Pribadi, Rifqi Azhar Fawih, Komarudin, Taopik \\ Zaenal Muttakqin, Wida Nengsih, Rosalinda, Windi Nabila Universitas Buana \\ Perjuangan Karawang if17.maulanamahmuddin@mhs.ubpkarawang.ac.id ${ }^{1}$
}

\begin{abstract}
Abstrak
Kuliah Kerja Nyata (KKN) merupakan bentuk kegiatan pengabdian kepada masyarakat oleh mahasiswa dengan pendekatan lintas keilmuan dan sektoral pada waktu dan daerah tertentu di Indonesia. Kuliah Kerja Nyata (KKN) yang berlangsung pada tanggal 10 Agustus 2020 hingga 31 Agustus 2020 bertujuan untuk memberikan pengalaman dan keterampilan kepada mahasiswa dalam

pembangunan dan pengembangan masyarakat pedesaan dengan mengimplementasikan ilmu, teknologi dan seni, serta melatih dan membuka wawasan mahasiswa dalam hidup bermasyarakat. Selain itu penulis ingin mengembangkan pelaku UMKM di Desa Rawagempol Wetan dengan membangun Rancang Bangun Pelayanan UMKM berbasis Website, karena UMKM desa memiliki peran cukup penting dalam pembangunan ekonomi dalam skala nasional. UMKM desa juga dapat menjadi solusi efektif dalam permasalahan ekonomi pada kelas kecil sampai menengah dan mampu mengurangi pengangguran dengan membuka lapangan pekerjaan baru.
\end{abstract}

Kata Kunci UMKM, Pelayanan Informasi, Website, Pengabdian Masyarakat

\begin{abstract}
Kuliah Kerja Nyata (KKN) are a from of community service activities by students with a cross-scientific and sectoral approach at certain times and regions in Indonesia. Kuliah Kerja Nyata (KKN) which took place on 01 August 202031 August 2020 aims to provide experience and skills to students in the development and development of rural communities by implementing science, technology and art, as well as training and opwning up student awareness in social life. In addition, the authors want to develop UMKM Service Designs because village UMKM have a fairly important role in economic development on a nation scale. Village UMKM can also be an effective solution to economic problems for the small to middle class and are able to reduce unemployment by opening new jobs.
\end{abstract}

Keywords UMKM, information Services, Website, Community Service 
Iin Lidia Putama Mursal, Maulana Mahmuddin, Muhammad Afif Firmansyah, Edwin Pribadi, Rifqi Azhar Fawih, Komarudin, Taopik Zaenal Muttakqin, Wida Nengsih,

Rosalinda, Windi Nabila

Vol. 3 No 1, Februari 2021

ISSN 2657-0203

e-ISSN 2686-0244

\section{PENDAHULUAN}

Desa Rawagempol Wetan merupakan salah satu desa yang terletak di Kecamatan Cilamaya Wetan sebelah utara Kota Kabupaten Karawang Provinsi Jawa Barat, dengan penghasilan utama masyarakatnya yaitu dibidang pertanian. Desa Rawagempol Wetan terbagi atas 4 Dusun dengan luas lahan pertanian 357,5 H serta jumlah masyarakat di Desa Rawagempol Wetan berada di angka 6.497 penduduk. Minimnya pelaku usaha mikro disana menjadi tolak ukur kemajuan didesa tersebut.

Menurut para ahli UMKM adalah singkatan dari Usaha Mikro dan Menengah yang mana merupakan satu model baru dalam kegiatan perniagaan atau perdagangan[1], data terakhir UMKM di Kabupaten Karawang yang diberikan oleh Dinas Perindustrian dan Perdagangan (Disperindag) mencapai angka 250 kepala keluarga. Kelemahan UMKM di Indonesia khususnya di Kota Karawang adalah pada aspek daya saing dan sumber daya manusia yang minim Pendidikan, disamping itu keadaan saat ini semakin sulit akibat 
Iin Lidia Putama Mursal, Maulana Mahmuddin, Muhammad Afif Firmansyah, Edwin Pribadi, Rifqi Azhar Fawih, Komarudin, Taopik Zaenal Muttakqin, Wida Nengsih,

Rosalinda, Windi Nabila

Vol. 3 No 1, Februari 2021

ISSN 2657-0203

e-ISSN 2686-0244

adanya Covid-19 dan juga meningkatnya krisis ekonomi serta pemutusan hubungan kerja (PHK) secara berkala. Faktor lain yang menjadi pengaruh turun nya pelaku UMKM di Desa Rawagempol Wetan salah satunya dalam sektor keuangan, peralatan, dan pemasaran yang menjadi dukungan jalannya usaha tersebut.

Untuk memudahkan pelaku UMKM di Desa Rawagempol Wetan, mahasiswa UBP Karawang yang sedang Kuliah Kerja Nyata (KKN) untuk pengabdian kepada masyarakat

mahasiswa UBP Karawang membuatkan sebuah rancang bangun sistem pelayanan informasi berbasis website bagi pelaku Usaha Mikro dan

Menengah (UMKM), yang didalamnya terdapat informasi, pembelajaran, hingga data UMKM yang berada di desa tersebut. Dalam pembuatan rancang bangun ini penulis menggunakan System Development Life Cycle (SDLC) dengan metode agile development.

\section{METODE}

Berdasarkan literatur dan jurnal-jurnal yang diperoleh penulis 
Iin Lidia Putama Mursal, Maulana Mahmuddin, Muhammad Afif Firmansyah, Edwin Pribadi, Rifqi Azhar Fawih, Komarudin, Taopik Zaenal Muttakqin, Wida Nengsih,

Rosalinda, Windi Nabila

Vol. 3 No 1, Februari 2021

ISSN 2657-0203

e-ISSN 2686-0244

itulah, maka penulis membuat kerangka berfikir dalam menyusun perencanaan strategis.

Sedangkan untuk mendukung pengembangan sistem informasi yang akan diimplementasikan di rancang bangun sistem pelayanan informasi berbasis website, menggunakan rancangan System Development Life Cycle (SDLC) dengan metode Agile Development.

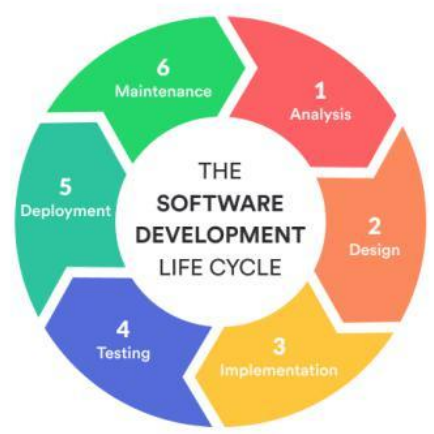

\section{Gambar 1. Metode Agile Develoment}

Pengertian metode agile adalah kombinasi dari model yang berulang dan incremental dengan focus pada proses adaptasi dan kepuasan pelanggan dengan pengiriman cepat bekerja prodik perangkat lunak[2]. Model pengembangan sistem Agile dipilih sebagai metode untuk pengembangan rancang bangun

sistem pelayanan informasi. pemilihan ini disadarkan pada situasi 
Iin Lidia Putama Mursal, Maulana Mahmuddin, Muhammad Afif Firmansyah, Edwin Pribadi, Rifqi Azhar Fawih, Komarudin, Taopik Zaenal Muttakqin, Wida Nengsih,

Rosalinda, Windi Nabila

Vol. 3 No 1, Februari 2021

ISSN 2657-0203

e-ISSN 2686-0244

mahasiswa yang sedang melakukan Kuliah Kerja Nyara (KKN) di Desa Rawagempol Wetan.

Dengan mengadaptasi model ini, diharapkan sistem bisa berhasil memajukan UMKM disana meskipun keterbatasan dalam pengembangan dan pengampu kebijakan.

\section{HASIL DAN PEMBAHASAN}

Langkah-langkah pembuatan simulasi dengan metode SDLC adalah sebgaai berikut : tahap analisis, tahap desain, tahap implementasi, tahap pengujian, dan tahap pemeliharaan[3].

\subsection{Tahap Analisis}

Pada tahap analisa data UMKM sudah dilakukan pada saat mahasiswa mencari data kuisioner dan menguploadnya di website prodeskel Kecamatan Cilamaya Wetan Desa

Rawagempol Wetan. Sebagai gambaran umum sistem ini, penulis membangun simulasi sistem dengan membuat rancangan flowmap sebagai berikut:

1. Admin akan melakukan rekap data UMKM yang sudah 
Iin Lidia Putama Mursal, Maulana Mahmuddin, Muhammad Afif Firmansyah, Edwin Pribadi, Rifqi Azhar Fawih, Komarudin, Taopik Zaenal Muttakqin, Wida Nengsih, Rosalinda, Windi

Nabila

Vol. 3 No 1, Februari 2021

ISSN 2657-0203

e-ISSN 2686-0244

terdaftar dan mempublikasikan data tersebut ke web dashboard.

2. Admin akan mempublikasikan materi tentang UMKM serta kegiatan UMKM.

3. Calon UMKM baru akan melihat data dan kegiatan yang diberikan oleh admin.

4. Jika calon UMKM berminat membuka peluang usahanya, calon UMKM melakukan pengisian data sebelum di berikan materi.

5. Setelah calon UMKM mendaftarkan diri, admin akan memberikan materi khusus.

\subsection{Tahap Desain}

Berdasarkan analisa yang sudah di lakukan pada proses dan dokumen flowmap yang dilakukan, maka

penulis merancang flowchart, Usecase Diagram, dan Class Diagram dengan sebagai berikut

\section{Flowchart}

Berikut ini adalah gambaran dari flowchart yang dapat dilihat pada gambar 2. Flowchart ini dibangun untuk alur admin pada saat mengakses dan menginput data pada website dashboard. 
Iin Lidia Putama Mursal, Maulana Mahmuddin, Muhammad Afif Firmansyah, Edwin Pribadi, Rifqi Azhar Fawih, Komarudin, Taopik Zaenal Muttakqin, Wida Nengsih, Rosalinda, Windi

Nabila

Vol. 3 No 1, Februari 2021

ISSN 2657-0203

e-ISSN 2686-0244

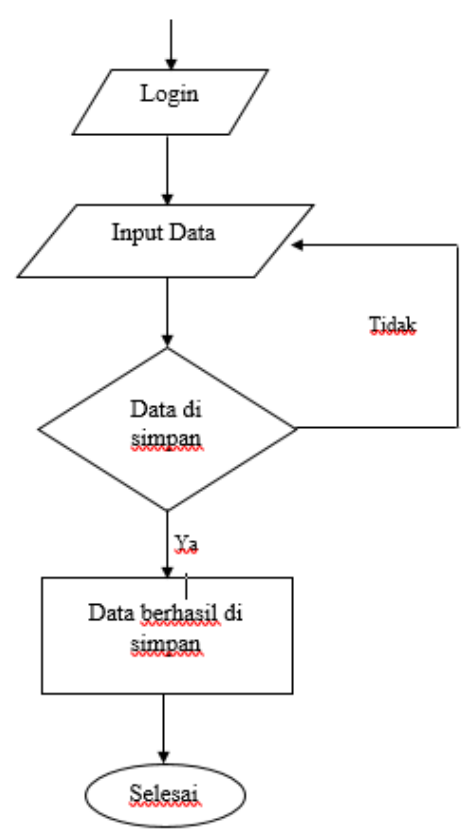

Gambar 2 Flowchart

\section{Usecase Diagram}

Berikut ini adalah gambaran dari usecase diagram yang dapat dilihat pada gambar 3. Yang mana admin hanya dapat melakukan kelola login, input data UMKM, dan

melakukan input kegiatan, pengaksesan ini mengacu pada saat pembuatan flowmap sebelumnya. 
Iin Lidia Putama Mursal, Maulana Mahmuddin, Muhammad Afif Firmansyah, Edwin Pribadi, Rifqi Azhar Fawih, Komarudin, Taopik Zaenal Muttakqin, Wida Nengsih,

Rosalinda, Windi Nabila

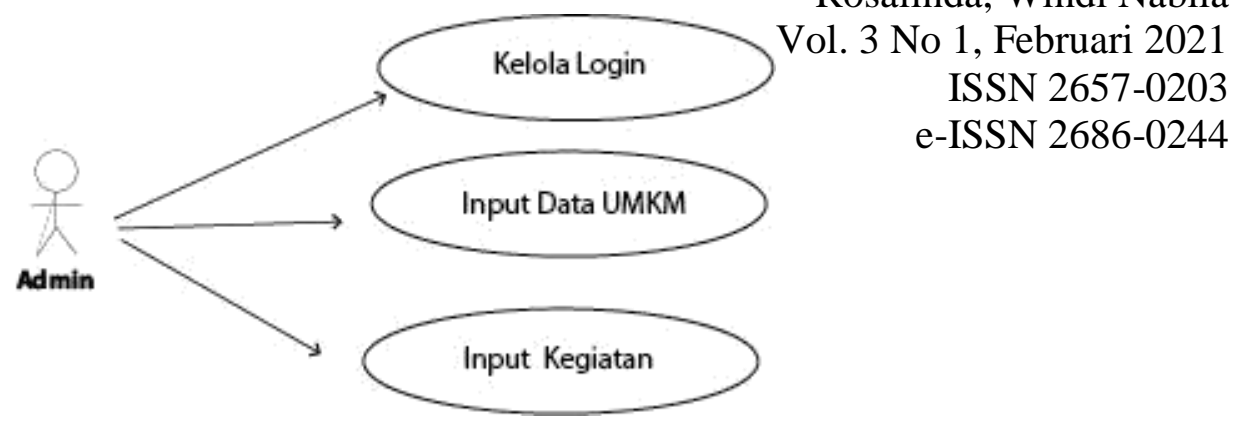

3. Class Diagram

Berikut dibawah ini adalah

gambaran dari class digram yang

dapat dilihat pada gambar 4 .

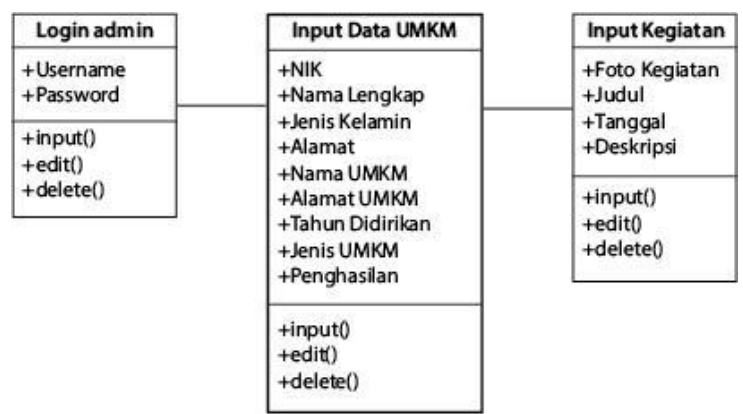

Gambar 4. Class Diagram

\subsection{Tahap Implementasi}

Pada tahap implementasi

dilakukan dengan menggunakan

native dimana kumpulan sintak

berhubungan dengan database.

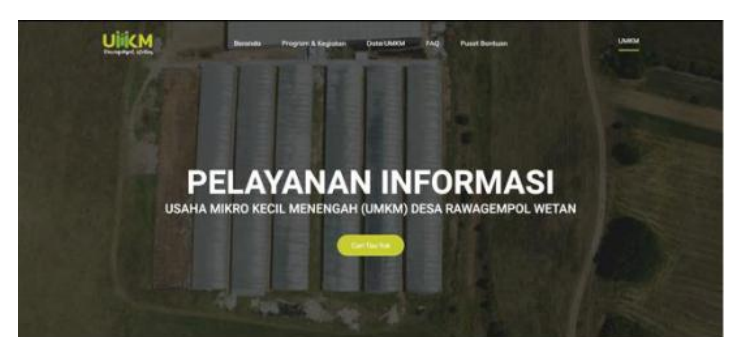

Gambar 5. Halaman Utama Website UMKM 
Iin Lidia Putama Mursal, Maulana Mahmuddin, Muhammad Afif Firmansyah, Edwin Pribadi, Rifqi Azhar Fawih, Komarudin, Taopik Zaenal Muttakqin, Wida Nengsih,

Rosalinda, Windi Nabila

Vol. 3 No 1, Februari 2021

ISSN 2657-0203

e-ISSN 2686-0244

Bagian ini merupakan desain layout

yang dibuat menggunakan html, php, css dan javascript, Seperti yang dapat dilihat pada Gambar 5,6,7. Pada Gambar 5 yaitu menampilkan tampilan utama pada user.

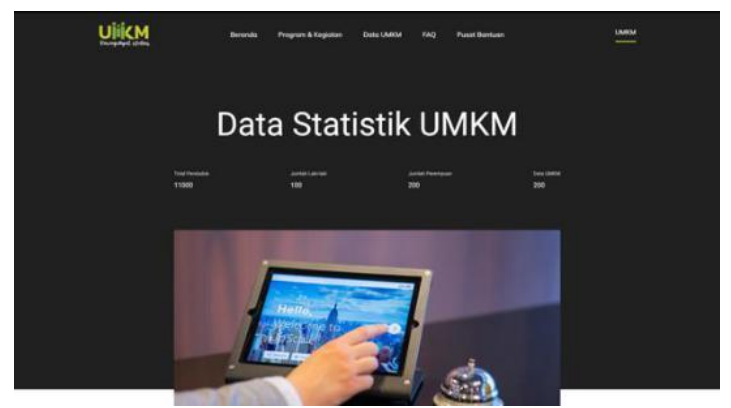

Gambar 6. Halaman Data Statistik

Pada Gambar 6 yaitu menampilkan tampilan data statistic UMKM terupdate yang di atur oleh admin.

Pada Gambar 7 yaitu menampilkan website dashboard, untuk melakukan update, dan menambahkan data maupun berita.

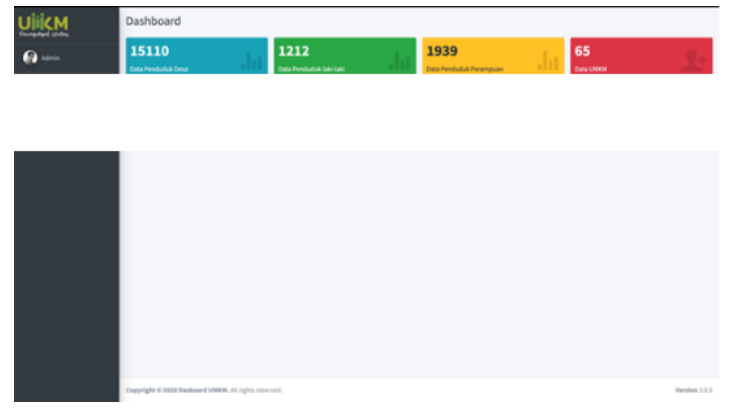

Gambar 7. Website Dashboard 
Iin Lidia Putama Mursal, Maulana Mahmuddin, Muhammad Afif Firmansyah, Edwin Pribadi, Rifqi Azhar Fawih, Komarudin, Taopik Zaenal Muttakqin, Wida Nengsih,

Rosalinda, Windi Nabila

Vol. 3 No 1, Februari 2021

ISSN 2657-0203

e-ISSN 2686-0244

\subsection{Tahap Pengujian}

Tahap pengujian ini terdiri atas

pengaplikasian sistem pada penggguna. Karna rancang bangun sistem pelayanan informasi UMKM ini belum sampai tahap pengjian terhadap pengguna, hanya di uji sesaat oleh penulis dikarnakan waktu yang dibutuhkan pada saat pengujian butuh waktu yang sangat panjang.

\subsection{Tahap Pemeliharaan}

Tahap terakhir pada metode SDLC adalah tahap pemeliharaan. Ada beberapa kegiatan yang dilakukan pada tahap ini, yaitu pemeliharaan sistem dengan pemeriksaan berkala, memperkaya fitur-fitur baru guna meningkatkan UMKM, ataupun bisa dengan pengembangan-pengembangan lainnya.

\section{KESIMPULAN DAN SARAN}

\subsection{Kesimpulan}

Berdasarkan pembahasan yang dipaparkan diatas, dapat disimpulkan bahwa :

1. Pentingnya kedisiplinan dan ilmu yang luar bagi pelaku UMKM serta dengan adanya rancang

bangun sistem pelayanan informasi UMKM ini dapat memajukan para pelaku UMKM disana.

2. Berdasarkan analisis, perancangan dan implementasi yang telah diuraikan, bahwa SDLC terbagi dalam lima tahap kegiatan, dan setiap kegiatan dalam SDLC dapat dijelaskan melalui tujuan dan hasil kegiatannya dengan jelas

3. Rancang bangun sistem pelayanan informasi UMKM ini dapat mudah digunakan dan memudahkan bagi UMKM di Desa Rawagempol Wetan.

\subsection{Saran}

Bila ada pengembangan selanjutnya dari rancang bangun sistem pelayanan informasi UMKM ini penulis memberikan saran untuk :

1. Mengembangkan fitur-fitur yang lebih bermanfaat dan dapat memajukan UMKM. 
Iin Lidia Putama Mursal, Maulana Mahmuddin, Muhammad Afif Firmansyah, Edwin Pribadi, Rifqi Azhar Fawih, Komarudin, Taopik Zaenal Muttakqin, Wida Nengsih,

Rosalinda, Windi Nabila

Vol. 3 No 1, Februari 2021

ISSN 2657-0203

e-ISSN 2686-0244

2. Dikarnakan waktu yang terbatas dalam pembuatan rancang bangun sistem ini, maka harus dilakukan pengujian terhadap pengguna dengan sesuai metode yang dipilih.

3. Melakukan analisis yang tepat dalam pembuatan rancangan basis data menggunakan ERD, UML,

Usecase Diagram, Class Diagram, dan sequence.

4. Dalam tahap implementasian,

penulis kedepannya dapat menggunakan framework website

adatidakmenyarankan

menggunakan metode native.

\section{DAFTAR PUSTAKA}

[1] A. Alimudin, A. Z. Falani, S.

W. Mudjanarko, and A. D. Limantara, "Analisis Pengaruh Penerapan Perspektif

Balanced Scorecard Terhadap Peningkatan Kinerja UMKM,” Ekonika J. Ekon.

Univ. kadiri, vol. 4, no. 1, p. 1, 2019, doi: 10.30737/ekonika.v4i1.337.

[2] R. Ilyas and Y. H. Chisnanto,

"Pengembangan Sistem

Informasi Penelitian LPPM Universitas Jenderal Achmad

Yani Dengan Agile SDLC,” Konf. Nas. Sist. Inf. 2018, pp. 974-979, 2018.

[3] I. G. S. Widharma,

"Perancangan Simulasi Sistem Pendaftaran Kursus Berbasis

Web Dengan Metode Sdlc,"

Matrix J. Manaj. Teknol. dan Inform., vol. 7, no. 2, p. 38, 2017, doi:

10.31940/matrix.v7i2.527. 